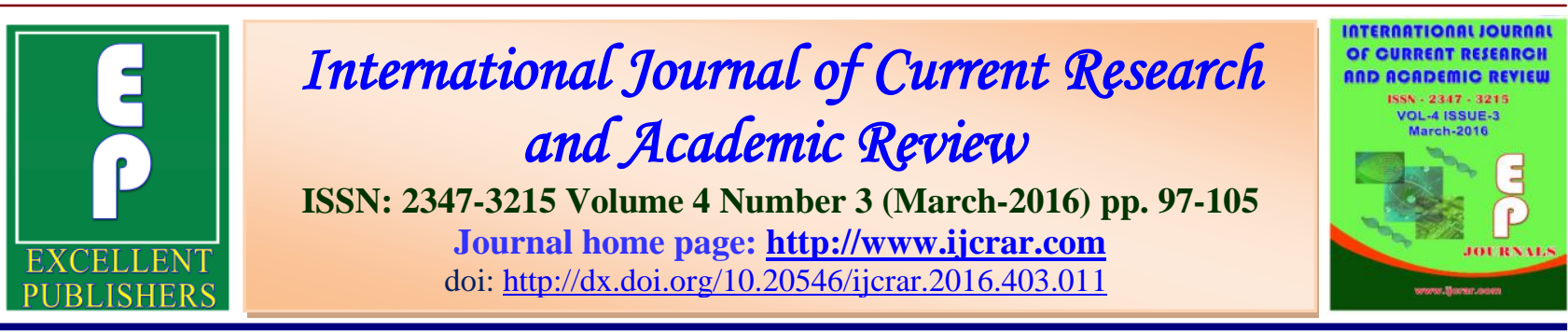

\title{
A Study to Effect of Organizational Citizenship on Customer Loyalty in Teaching Hospitals of the Ahvaz Jundishapur University of Medical Sciences in 2015-2016
}

\section{Ebrahim Cheraghi $^{1}$ and Alirezadadgarinejad ${ }^{2} *$}

${ }^{1}$ Department of Marketing Management, College of humanities Science, Ahvaz Branch, Islamic Azad University, Ahvaz, Iran

${ }^{2}$ Department of accounting, Masjedsoliman branch, Islamic Azad University, Ahvaz, Iran

\section{*Corresponding author}

\begin{tabular}{|l|l|}
\hline \multirow{2}{*}{ KEYWORDS } & A B S T R A C T \\
\cline { 2 - 3 } & Org
\end{tabular}

Organizational citizenship, Hospital, Service quality, Customer loyalty.
Organizational citizenship is individual and voluntary behavior for which no remuneration has been directly considered in the official payment system, nevertheless it improves the organizational effectiveness and efficiency. This study aimed to effect of organizational citizenship on customer loyality in the selected teaching hospitals of Ahvaz Jundishapur University of Medical Sciences. This study was a descriptive-analytic cross sectional study. Sampling the hospital staff was randomly done from the list of personnel. Sampling the customers was non-randomly (available) done. Data collection tools were two questionnaires of the organizational citizenship of staff and the customer questionnaire including customer loyalty. Data were assessed using independent T-test, ANOVA, Spearman correlation and linear regression analysis using the statistical software SPSS 22. The level of statistical significant difference was considered 0.05. In this study, we had invited 129 hospital staff and 370 people who were recipients of their service in this study. The average score of organizational citizenship was $42.82 \pm 2.9$. The relationship between demographic factors of sex and education and organizational citizenship was not significant $(\mathrm{P}>0.05)$. But in terms of chivalry, the age gap and in terms of the civil behavior-organizational behavior, marital status were statistically significant $(\mathrm{P}<005)$. The results showed that there was a statistical significant relationship between the customer loyalty and the organizational citizenship $(\mathrm{P}<0.001)$. The results showed that there was a positive relationship between organizational citizenship and customer loyalty. Therefore, for hospital managers, it is necessary to try to provide job satisfaction and organizational justice so that improving organizational citizenship of staff leads to improving the customer loyalty which is a factor to survive the system. 


\section{Introduction}

Organizational citizenship first was presented to the world of science by Batman and Organ in the early 1980s (Toure, 2006). This field of science consists of a set of voluntary behaviors that staff has for both the organization and customers. These activities are not a part of the requirements of the role of the staff in the work environment and no rumination is directly considered for it by the formal system (Eslamy et al., 2007; Bienstock et al., 20003). However, the researchers state that Organizational citizenship behavior (OCBs) is one of the basic factors in productivity, efficiency and success of any organization (Nejat et al., 2009).

With increasing the competition between hospitals to gain more market share, hospital managers are forced to find some ways to gain more customer satisfaction and loyalty. Because keeping the old customers is much less expensive than finding new ones which is usually a complex and high-cost process (Yoon and Suh, 2003).

In this context, the role of staff in this competitive market, is not covert to anyone. Lack of responsible staff to deliver organizational goods and services, in this competitive market, leads to serious problems for them. This issue can be more clearly seen in the service organizations (Salehi et al., 2012). Given that the intangible hospital services, it is probably hard for most customers to fully understand and evaluate the products they want to buy. Similarly, for the most sellers, it is hard to highlight the benefits of their products to their customers. So for a seller, it is necessary to provide the right information and proper guidance to the customers to make the right decision. Only an honest seller can earn customers' trust (Rashidi and Rahmani, 2014).
Over the past decade, several studies have been conducted on the related prerequisites to OCBs including job satisfaction, trust, organizational justice, organizational commitment, etc., but less attention has been paid to its impact on the perception of service quality, customer satisfaction and loyalty. Therefore this study was designed to investigate the impact of organizational citizenship behavior on perception of service quality and customer satisfaction and loyalty.

\section{Materials and Methods}

\section{Introducing the Research Community}

In this study, the research community consisted of employed staff of teaching hospitals affiliated to the Ahvaz University of Jundishapur and their customers.

\section{Type of Study and Sample Selection}

This study was a descriptive-analytic crosssectional study. Sampling the hospital staff was randomly performed from the list of personnel. Sampling the customers was nonrandomly (available) performed.

\section{Inclusion Criteria}

Being employed officially or on a contract in the teaching hospitals affiliated to Ahvaz Jundishapur University of Medical Sciences

Willingness to participate in the study

For service recipients (patients): willingness to participate in the study

\section{Exclusion Criteria}

Willingness to participate in the study for staff and service recipients 
The method of determining the sample size

To determine the sample size, this formula: $\mathrm{n} \geq\left(\mathrm{p}(1-\mathrm{p}) \mathrm{Z}_{-}(\alpha / 2)^{\wedge} 2\right) / \varepsilon^{\wedge} 2$ was used.

$\mathrm{n}=$ sample size,

$=$ Margin of error of $5 \%$

= Accuracy of measurement,

$\mathrm{p}=$ proportion of the population that has the desired feature,

$(\mathrm{p}-1)=$ proportion of the population that does not have the desired feature,

$\left(Z_{-}(\alpha / 2)\right)=$ the probability was normal.

The level of confidence was 95 percent which equals to 1.96 . p-1 equals to 50 percent and the level of error (d) the precision of the acceptable error bound was considered 50 percent. The sample size was 384.

\section{Data Collection Method}

Data measuring tools were two separate questionnaires. The Organizational citizenship behavior was completed by the employed staff of teaching hospitals affiliated to Ahvaz Jundishapur University of Medical Sciences and the perception of services quality, customer satisfaction and loyalty questionnaire were completed by services recipients.

Organizational citizenship behavior was measured using Netemeyer (1997) questionnaire in four dimensions of chivalry (3 items- questions 1,2,3); civil behavior (3 items- questions $4,5,6$ ), work ethic (3 itemsquestions 7,8,9) and altruism (3 itemsquestions 10,11,12).
The customer perception questionnaire consists of service quality using SERVQUAL index Parasaramn (1985) in five categories: Tangibility (4 items questions $1,2,3,4$, reliability (5 items questions, 5, 6,7,8,9), accountability (4 items - questions $10,11,12,13)$ and empathy (5 items - questions 14,15,16,17,18) and confidence (4 items -Svalat 19, 20,21,22).

The customer satisfaction index was measured derived from Zytmal index et al (1996) using Malvels (1997) nine-item index (questions 23, 24, 25, 26, 27, 28, 29, $30,31)$ and behavioral intentions ( 2 items 32,33 ) and customer loyalty (4 items $34,35,36,37)$.

Reliability of the questionnaires was calculated using Cronbach's alpha. The Cronbach's alpha coefficient for the organizational citizenship behavior questionnaire was reported $0 / 50$ and for the customer questionnaire was reported 0/97.

\section{Data Analysis Method}

In descriptive statistics, mean, standard deviation, percentage frequency were used and in analytical statistics, independent sample $t$ test was used to relate the qualitative dual-mode variable to the quantitative variable, and to relate the multistate qualitative variable to the quantitative variable, one way ANOVA test and to relate the two quantitative variables, the correlation test was used.

Finally, the data were measured using the linear regression test to remove the confounding factors at the significant level of 0/05 with statistical software SPSS 22. Kolmogorov-Smirnov test was also used to check the normality of the data. 


\section{Results and Discussion}

\section{The Characteristics of the Subjects}

\section{A: staff under study}

In this study, 129 hospital staff were entered in the study. The age group below 30 years had the highest frequency. The majority of the subjects were male $(69.8 \%)$. In terms of marital status, single people had a higher frequency $(55.8 \%)$. Most of the participants in the study were nurse $(44.2 \%)$ and undergraduate $(47.3 \%)$.

\section{B: Customers or service recipients}

In our study, 370 service recipients were participated in the study. Most of them were 20-30 years old. In terms of marital status, married people have the highest frequency. About one third of the service clients were unemployed $(35.4 \%)$ and most of them have diploma certificate $(46.8 \%)$ (Table 1$)$.

\section{Organizational Citizenship}

Organizational citizenship and its dimensions

To select the appropriate tests and also determine the prerequisites of application of tests, the normality of the data was evaluated using Kolmogorov-Smirnov test. In this test, the average score in organizational citizenship behavior index was abnormal $(\mathrm{P}<0.05)$, but given that the sample size, more than 100 parametric tests were used to analyze the data.

The average score in the organizational citizenship behavior index and its dimensions including chivalry, civic behavior, work ethic and altruism in staff were $42.82,5.64,11.70,13.09$, and 12.38 respectively.
The findings indicated that the average score of all dimensions of organizational citizenship behavior in females, except the civic behavior, were higher, but no significant statistical difference was observed between the average organizational citizenship behavior and its dimensions in both sexes $(\mathrm{P}>0.05)$.

And also, the findings showed that the highest average score of organizational citizenship behavior was for staff under 30 years old. The most average score of chivalry, altruism and civic behavior were seen in the group age of under 30 years and the average score of work ethic and civic behavior were observed in the age group of 30-40 years. No statistical significant difference was observed between the average score of organizational citizenship behavior, the dimensions of civic behavior, work ethic and altruism in different age groups $(\mathrm{P}>0.05)$, but there was a statistical significant difference between the average score of chivalry and age $(\mathrm{P}<0.05)$.

The average score of organizational citizenship behavior, work ethic and civic behavior in married people and the average score of altruism and chivalry in single people were higher. In terms of civic behavior, statistical significant difference was observed between two groups $(\mathrm{P}<0.05)$. The average score of chivalry, altruism, organizational behavior in graduated staff and the average score of civic behavior and work ethic in staff with diploma were higher. There was no significant difference between organizational behavior and its dimensions and the variable of education $(\mathrm{P}>0.05)$.

\section{Perception of the Quality of Customer Service}

The perception of the quality of customer service dimensions consisted of tangibility, 
Int.J.Curr.Res.Aca.Rev.2016; 4(3): 97-105

reliability, accountability, empathy and peace of mine. The average score of perception of the quality of customer service, tangibility, reliability, accountability, empathy and peace of mind were respectively 91.22, 18.98, 16.24, 21.20, 21.07, and 17.13 (Table 3).

The effective factors on perception of the quality of the customer service

In analysis was performed using the Spearman correlation, the coefficient correlation between the perception of quality of customer service and organizational citizenship behavior was 0.66 and the relationship between these two variables was statistically significant $(\mathrm{P}<0.001)$.

The findings of the analysis using line regression test along with removing the confounding factors also showed that the demographic variables were not effective on the perception of the quality of the customer service, but the organizational behavior was significantly related to the perception of the quality of the customer service $(\mathrm{P}<0.001)$ (Table 4).

\section{Customer Satisfaction}

The average score of the customer satisfaction in service receivers of the hospitals considered for this study was 38.67 \pm 5.19 .

To investigate the normality of the data, Kolmogorov-Smirnov test was used. In this test, the average score of customer satisfaction was abnormal $(\mathrm{P}<0.05)$, but given that the sample size, more than 100 parametric tests were used to analyze the data.

In the analysis performed using the Spearman correlation test, correlation coefficient between the customer satisfaction and the organizational citizenship behavior was 0.83 and the correlation between these two variables was statistically significant $(\mathrm{P}<0.001)$.

The findings of the analysis using the line regression test along with removing the confounding factors also showed that the demographic variables of the customers was not effective on the customer satisfaction, but the organizational behavior was significantly related to customer satisfaction $(\mathrm{P}<0.001)$ (Table 4).

\section{Behavioral Intentions}

Mean and standard deviation of the behavioral intention score in service receivers of the hospitals investigated in this study was $6.81 \pm 1.73$.

The effective factors on the behavioral intentions

The findings of the analysis using the line regression test along with removing the confounding factors also indicated that between the demographic variables and the average score of the behavioral intention and also between the average score of the behavioral intentions and the organizational behavior, there was not a statistically significant relationship $(\mathrm{P}>0.05)$ (Table 4).

\section{Customer Loyalty}

The average score of customer loyalty in service receivers in the hospitals under study was $16.01 \pm 2.43$.

\section{Effective Factors on Customer Loyalty}

The findings of the analysis of the data with removing the confounding factors in lineregression test showed that among the demographic variables and the average score 
Int.J.Curr.Res.Aca.Rev.2016; 4(3): 97-105

of the organizational behavior, the average score of the organizational score was the only effective variable on customer loyalty $(\mathrm{P}<0.001)$ (Table 5).

Table.1 Demographic Characteristics of Customers or Service Recipients of Medical Centers in Ahvaz

\begin{tabular}{|c|c|c|}
\hline Variable & Number & Percent \\
\hline Age & & \\
\hline Below 20 & 47 & 12.7 \\
\hline $20-30$ & 118 & 31.9 \\
\hline $31-40$ & 97 & 26.2 \\
\hline $41-50$ & 59 & 15.9 \\
\hline More than 50 & 49 & 13.2 \\
\hline Sex & & \\
\hline Male & 181 & 48.9 \\
\hline Female & 189 & 51.1 \\
\hline Marital status & & \\
\hline Single & 113 & 30.5 \\
\hline Married & 257 & 69.5 \\
\hline Education & & \\
\hline Illiterate & 116 & 31.4 \\
\hline Diploma & 173 & 46.8 \\
\hline Academic & 81 & 21.9 \\
\hline Occupation & & \\
\hline Unemployed & 131 & 35.4 \\
\hline Clerk & 86 & 23.2 \\
\hline Self-employed & 92 & 24.9 \\
\hline Housewife & 61 & 16.5 \\
\hline
\end{tabular}

Table.2 Distribution of Organizational Citizenship and its Dimensions

\begin{tabular}{|c|c|c|c|c|}
\hline & Number & Mean & $\begin{array}{c}\text { Standard deviation of the } \\
\text { mean }\end{array}$ & Standard deviation \\
\hline Chivalry & 129 & 5.64 & 0.12 & 1.34 \\
\hline Civil behavior & 129 & 11.70 & 0.13 & 1.47 \\
\hline Work ethic & 129 & 13.09 & 0.10 & 1.18 \\
\hline Altruism & 129 & 12.38 & 0.14 & 1.64 \\
\hline Organizational citizenship & 129 & 42.82 & 0.26 & 2.9 \\
\hline
\end{tabular}


Int.J.Curr.Res.Aca.Rev.2016; 4(3): 97-105

Table.3 The Factors Effective on Perception of Service Quality and Customer Satisfaction

\begin{tabular}{|c|c|c|c|c|}
\hline \multicolumn{2}{|c|}{ Variable } & B & t-test & P-value \\
\hline \multirow{7}{*}{$\begin{array}{l}\text { Perception of the quality of } \\
\text { the customer service }\end{array}$} & Constant & 41.86 & 10.93 & $0.001<$ \\
\hline & Age & -0.21 & -0.97 & 0.33 \\
\hline & Sex & -0.88 & -1.74 & 0.08 \\
\hline & Marital status & 0.03 & 0.05 & 0.95 \\
\hline & Education & -0.36 & -1.02 & 0.31 \\
\hline & Occupation & 0.16 & 0.71 & 0.48 \\
\hline & Organizational behavior & 1.21 & 14.81 & $0.001<$ \\
\hline \multirow{7}{*}{ Customer satisfaction } & Constant & 8.21 & 4.94 & $0.001<$ \\
\hline & Age & -0.05 & -0.48 & 0.63 \\
\hline & Sex & -0.16 & -0.74 & 0.46 \\
\hline & Marital status & -2.63 & 1.25 & 0.21 \\
\hline & Education & 0.34 & 0.66 & 0.51 \\
\hline & Occupation & 0.10 & -0.46 & 0.65 \\
\hline & Organizational behavior & 0.81 & 22.90 & $0.001<$ \\
\hline \multirow[b]{7}{*}{ Behavioral intentions } & (constant) & 9.96 & 4.11 & $0.001<$ \\
\hline & Age & -0.23 & -1.46 & 0.14 \\
\hline & Sex & -0.17 & -0.53 & 0.59 \\
\hline & Marital status & -0.10 & -0.25 & 0.80 \\
\hline & Education & -0.15 & -0.70 & 0.49 \\
\hline & Occupation & 0.08 & 0.62 & 0.53 \\
\hline & Behavior & -0.06 & -1.18 & 0.24 \\
\hline
\end{tabular}

Table.4 Effective Factors on Customer Loyalty

\begin{tabular}{|c|c|c|c|}
\hline Variable & B & t-test & p-value \\
\hline Constant & -2.55 & -1.01 & 0.31 \\
\hline Age & -0.04 & -0.27 & 0.78 \\
\hline Sex & -0.25 & -0.77 & 0.43 \\
\hline Marital status & -0.60 & -1.47 & 0.14 \\
\hline Education & -0.24 & -1.05 & 0.30 \\
\hline Occupation & -0.25 & -1.77 & 0.07 \\
\hline Organizational citizenship & 0.49 & 9.19 & $0.001<$ \\
\hline
\end{tabular}

With increasing the competition between hospitals to gain more market share, hospital managers are forced to find some ways to gain more customer satisfaction and loyalty. In this context, the role of staff is not covert to anyone. Lack of responsible staff to deliver organizational goods and services, in this competitive market, leads to serious problems for them. This issue can be more clearly seen in the service organizations (Salehi et al., 2012). Okpera in his study showed that the staff commitment was 
affected by staff satisfaction and this satisfaction affects the service quality. Providing high quality service attracts customers' attention and attracting the customers' satisfaction in the long run leads to customer loyalty (Bitner, 2005; Okpara, 2004). This finding was consistent with Nejat's et al. (Nejat et al., 2009) findings.

And also, Rezaie Dizgah et al. (Rezaii Dizgah et al., 2012) in an investigation of the relationship between organizational citizenship behavior and the quality of the service which was performed using the quantitative method among 780 persons of staff and customers of 22 state and 4 private hospitals in Gilan province, concluded that there was a direct relationship between organizational citizenship behavior and the quality of services in the hospitals and improving the organizational citizenship behavior in hospitals, customer satisfaction of the quality of the provided services can be observed. The findings of these studies were consistent with the findings of the present study which showed a significant relationship between organizational citizenship behavior and customer satisfaction.

The findings of the present study showed that the customer perception of the quality of the services depended on organizational citizenship behaviors. This finding was consistent with the findings of the Castro's study (Castro et al., 2004). Also, Yoon in his study proved that customer perception of quality influences his/her loyalty and efficiency of the organization (Yoon and Suh, 2003).

The findings of the present study also showed that the average score of organizational citizenship behavior in women was higher than it in men which could be driven from their organizational commitment and job satisfaction. These findings were not consistent with the findings of the study of Mayel Afshar et al. (Mayel Afshar et al., 2012) which indicated that women's suspicion in work place leads to a decline in their organizational citizenship behavior.

In this study, the amount of organizational citizenship behavior in the age group under 30 years was higher which could be driven from their academic training and the managers' more attention to it. But no significant difference between age and the amount of organizational citizenship behavior was obtained.

In our study, the amount of organizational citizenship behavior in marred people was higher. One reason could be their inclination toward cooperation and their responsibility. These findings were consistent with the Mayeli Afshar's study (Mayel Afshar et al., 2012).

In graduated staff, the organizational citizenship behavior was higher and their better situation, in terms of organizational status and salary and accordingly job satisfaction, could be its reason. The findings of the Mayel Afshar's study also showed that increasing salary led to more satisfaction and efficiency in the subjects and it would be effective in the level of organizational citizenship behavior.

\section{Conclusion}

Considering different dimensions of organizational citizenship behavior and exactly identifying its dimensions have useful consequences for planning, organizing, increasing efficiency and better performance. Therefore, hospitals should use appropriate teaching programs to improve this behavior and also remuneration should be considered for those staff who do their duties regularly and 
according to the standards to be more encouraged to have more desirable organizational behavior.

\section{Acknowledgement}

The authors of this paper thank all people who participated in this research.

\section{References}

1.Toure, N. 2006. Factors Vbrrsy citizenship behavior and its relationship with organizational performance. J. Cultural Management, 12: 31-64.

2.Eslamy, H., Sayar, A., Kazemy Akhavan, B. 2007. Organizational citizenship behavior. Montyly Ofogh, 37.

3.Bienstock, C.C., Demoranville, W.C., Smith, K.R. 2003. Organizational citizenship behavior and service quality. J. Services Marketing, 17(4): 357-378.

4.Nejat, Seyyed Amir Reza, Kosar Neshan, Mohammad Reza, Mirzade, Akbar. 2009. The effect of organizational citizenship behavior on the service quality (case study: Travel Agencies in Tehran). Business studies, (35): 72-84.

5.Yoon, M., Suh, J. 2003. Organiziational citizenship behaviors and service quality as external effectiveness of contact employees. J. Business Res., 56: $597-$ 611.

6.Salehi, Sabour, Abbasi, Mohammad Reza. 2012. The effect of internal marketing on the customer satisfaction in the insurance industry (studying the insurance companies in the insurance companies in Tehran). Insurance J., 2: 145-176.

7.Rashidi, H., Rahmani, Z.2014. Brand and its effect on customer loyalty. Eco. J., 9-10, 65-70.

8.Bitner, M.J. 2005. Evaluating services encounters the effect of physical surrounings and employee responses. $J$. Marketing, 54: 69-82.

9.Okpara, J.O. 2004. Job satisfaction and organizational commitment. $\mathrm{X}$ international conference Montreux, Switzerland, 2004 Roland f. Rewarding Employee Loyalty, Organization Behaviour J., 8-3, 486-503.

10.Rezaii Dizgah, Morad, Azade Del, Mohammad Reza, Farahbud, Farzin, Sanaz, Gharedaghi. 2012. Studying the relationship between organizational citizenship behavior and service quality in Gilan province hospitals. Gilan Univ. Med. Sci. J., 20(80): 10-15.

11.Castro, C.B., Armario, E.M., Ruiz, D.M. 2004. The influence of employee organizational citizenship behavior on customer loyalty. Int. J. Service Industry Management, 115: 27-53.

12.Mayel Afshar, Mahnaz, Poor Reza, Abolghasem, Memarpoor, Mahdi. 2012. Studying the effect of demographic characteristics on organizational citizenship behavior on selected teaching hospitals staff of Tehran Medical Sciences University. Hospital Quarterly, no. 2, Summer. 45: 51-62.

\section{How to cite this article:}

Ebrahim Cheraghi and Alirezadadgarinejad. 2016. A Study to Effect of Organizational Citizenship on Customer Loyalty in Teaching Hospitals of the Ahvaz Jundishapur University of Medical Sciences in 2015-2016. Int.J.Curr.Res.Aca.Rev.4(3): 97-105. doi: http://dx.doi.org/10.20546/ijcrar.2016.403.011 